\title{
DICÇÕES POÉTICAS CONTEMPORÂNEAS EM TRÊS ATOS ${ }^{1}$
}

\author{
Contemporary Poetic Diction in three Acts
}

\author{
André Natã Mello BOTTON \\ Programa de Pós-Graduação em Letras \\ Pontifícia Universidade Católica do Rio Grande do Sul \\ andre.botton@edu.pucrs.br \\ https://orcid.org/0000-0002-2136-7544
}

\begin{abstract}
RESUMO: O presente artigo toma como objeto de estudo três poemas ("Pai e eu", de Edson Veóca, "Um presente para a Elite Brasileira", de Cláudia Canto, e "Conflito", de Atrês) publicados, respectivamente, em cada uma das três edições especiais da Revista Caros Amigos/ Literatura Marginal: a cultura da periferia - Atos I, II e III, de 2001, 2002 e 2004. Esta reflexão está dividida em três partes: uma análise sócio-histórica a respeito do projeto literário da Revista, em seguida, uma proposta de leitura de cada um dos poemas e, por fim, uma discussão ampla relacionada ao projeto político da Revista evidenciado nos textos literários. A argumentação está embasada na teoria de Pierre Bourdieu a respeito do campo literário, associada a discussões prévias sobre as edições especiais da Caros Amigos/Literatura Marginal, bem como em estudos sobre literatura marginal das periferias. PALAVRAS-CHAVE: Poesia; Literatura Marginal das Periferias; Revista Caros Amigos.
\end{abstract}

ABSTRACT: The present article takes as object of study three poems ("Pai e eu", by Edson Veóca, "Um presente para a Elite Brasileira", by Cláudia Canto, and "Conflito", by Atrês) published, respectively, in each of the three special editions of Caros Amigos Magazine/Literatura Marginal: a cultura da periferia - Atos I, II e III, from 2001, 2002 and 2004. This reflection is divided into three parts: a socio-historical analysis of the literary project of the magazine, then, a reading proposal of each of the poems and, finally, a broad discussion related to the magazine's political project highlighted in the literary texts. The argument is well-founded on Pierre Bourdieu's theory about the literary field, associated with previous discussions about the special issues of Caros Amigos/Literatura Marginal, as well as studies on marginal literature of the peripheries.

${ }^{1}$ O presente trabalho foi realizado com apoio do CNPq, Conselho Nacional de Desenvolvimento Científico e Tecnológico - Brasil.

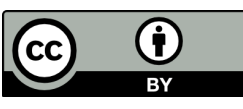


KEYWORDS: Poetry; Marginal Literature from Peripheries; Caros Amigos Magazine.

O poeta é livre. Coloquemo-nos do seu ponto de vista, e vejamos.

Victor Hugo, prefácio de As orientais (1829)

A revolução será silenciosa e determinada como ler um livro à luz de velas

em plena madrugada.

Ferréz, Contestação, Caros Amigos/Literatura Marginal, Ato III (2004)

Se, para Batteux (2009, p. 95) - dentro do contexto francês do século XVIII -, "a finalidade da poesia é agradar, e agradar agitando as paixões", os poemas aqui selecionados, por outro lado, não ficam condicionados apenas à condição de agradar. Eles, para além dessa concepção, são exemplos da agitação que a literatura brasileira contemporânea vem despertando nos últimos tempos por vias distintas: incômodos, malestares, novas visões (ou dicções) e fazeres estéticos. Contudo, aquele mesmo princípio enunciado em meados do século XVIII ainda se mantém: os mais diversos sentimentos são agitados por vozes distintas que se unem em torno de um mesmo projeto literário.

Nos últimos vinte anos, a literatura marginal das periferias vem se consolidando dentro do sistema literário brasileiro como um dos mais atuantes movimentos estéticos, ganhando, com isso, destaque em feiras, eventos, editoras e demais instituições do campo literário. Em uma mirada histórica, há momentos específicos que contribuíram para a grande recepção hoje vivenciada pela literatura marginal, dentre eles: a publicação dos romances Cidade de Deus (1997), de Paulo Lins, e Capão pecado (2000), de Ferréz; a atuação constante de agentes ${ }^{2}$ nos saraus das periferias de São Paulo; a publicação de três edições especiais da revista Caros Amigos/Literatura Marginal em 2001, 2002 e 2004, com organização de Ferréz.

O foco do presente texto é apresentar, em linhas gerais, o que foi o projeto da revista Caros Amigos/Literatura Marginal e ler, nesse contexto, três poemas de cada uma das edições para, em seguida, refletir sobre esses textos de maneira conjunta, na tentativa de levantar novas visões e posicionamentos sobre o fazer literário na contemporaneidade.

\footnotetext{
${ }^{2}$ O termo "agente" é entendido aqui a partir da acepção de Pierre Bourdieu (1996) relativa à trajetória que o indivíduo possui vinculada ao habitus e ao percurso histórico no campo literário. Revista X, v. 16, n. 6, p. 1843-1860, 2021. 


\section{CAROS AMIGOS/LITERATURA MARGINAL}

Ferréz - no contexto do início dos anos 2000 - se consolida relativamente atuando em diversos setores culturais: música, literatura e produção cultural no Capão Redondo - bairro localizado na Zona Sul da cidade de São Paulo. Ao mesmo tempo, ganha uma coluna em jornal de prestígio, a Folha de São Paulo. Além disso, a partir de 2000, Ferréz passa a colaborar mensalmente na Revista Caros Amigos ${ }^{3}$ e, em 2001, organiza uma edição especial, além de outras duas, em 2002 e 2004: são os três números da Revista Caros Amigos/Literatura Marginal: a cultura da periferia - Atos I, II e III.

De modo geral, os três volumes reúnem escritores de todo o Brasil que se reconhecem enquanto marginais: desde dona Laura, em Pelotas/RS, passando por Káli-Arunóe e Maria Inziné, da etnia Terena, em Miranda/MS, até Oni, em Recife/PE - para citar apenas alguns e exemplificar a expansão do trabalho. Ao contribuir para a ampliação do aceite de autores, desse modo, a organização também alarga a noção de escritor "marginal", não a condicionando apenas à geografia dos espaços, mas voltada à marginalidade social (dentro dos grupos minoritários sociais) e no que se refere à falta de acesso às casas editoriais ${ }^{4}$ :

Debitada da conta da Geração do Mimeógrafo, a nova configuração da ideia de Literatura Marginal tem muito pouco a dever. A iniciar pela transposição discursiva do que seja marginalidade: ela não se situa, como se disse antes, num estilo de vida, solução para um sufoco contextual, que leve a um descrédito estrutural e ao desbunde. Agora, ela é vista como um dado espacial e sócio-histórico. Dito de outra forma: ela não é um estilo circunstancial de vida, ela é a própria vida, de cuja condição não se pode abdicar tão facilmente, pois é fenômeno estrutural e estruturante. (SILVA, 2011, p. 102)

Considerada, então, como "fenômeno estrutural e estruturante", pode-se pressupor, dentro desse contexto teórico bourdiano, a Caros Amigos/Literatura Marginal como devir

\footnotetext{
3 “A revista Caros Amigos foi criada em 1997 pela Editora Casa Amarela, com a proposta de apresentar entrevistas com personalidades de opiniões 'críticas' e 'independentes' sobre o meio em que se destacam. Os temas abordados são classificados como de interesse geral, mas privilegiam as áreas política, econômica e artística. Com circulação nacional e periodicidade mensal, a tiragem média produzida é de cinquenta mil exemplares" (NASCIMENTO, 2009, p. 53). Em dezembro de 2017, o editorial da revista anunciou o fim das edições impressas. Contudo, até o momento desta pesquisa, não foi possível encontrar o site ou a versão digital da Caros Amigos.

${ }^{4}$ Nunca é demais lembrar que o presente trabalho está voltado apenas para a produção literária marginal das periferias. Contudo, conforme afirmado acima, a produção emergente nesse início de século amplia conceitos e modifica o horizonte de possibilidades de produção artística.
} 
produtor de um habitus de produção cultural voltado para as manifestações artísticas marginais. "Como produto da história", diz Bourdieu (2003, p. 68), "o habitus produz práticas individuais e coletivas, produz história em conformidade com os esquemas engendrados pela história". As edições se constituem, desse modo, enquanto práticas individuais de um agente, voltadas para a organização coletiva de um produto cultural dentro de um campo artístico, um devir de novas estruturas oriundas dos limites do campo literário brasileiro. "Tanto os críticos literários como os próprios escritores coincidem em apontar esses números especiais da Revista Caros Amigos como o início de uma nova fase em relação à literatura dos setores de trajetória não letrada" (TENNINA, 2017, p. 27).

O trabalho editorial dos três Atos é composto por desenhos de artistas já reconhecidos ou por leitores que querem expor seus trabalhos. Os gêneros dos textos são diversos, em sua maioria contos, crônicas e poemas. No total, os três números reúnem 80 textos de 48 autores. O primeiro número teve tiragem de 30 mil exemplares; o segundo e o terceiro, de 20 mil cada. As revistas foram comercializadas, respectivamente, por R\$ $4,90, \mathrm{R} \$ 5,50$ e $\mathrm{R} \$ 7,00$.

Revistas Caros Amigos/Literatura Marginal - Atos I, II e III, respectivamente.

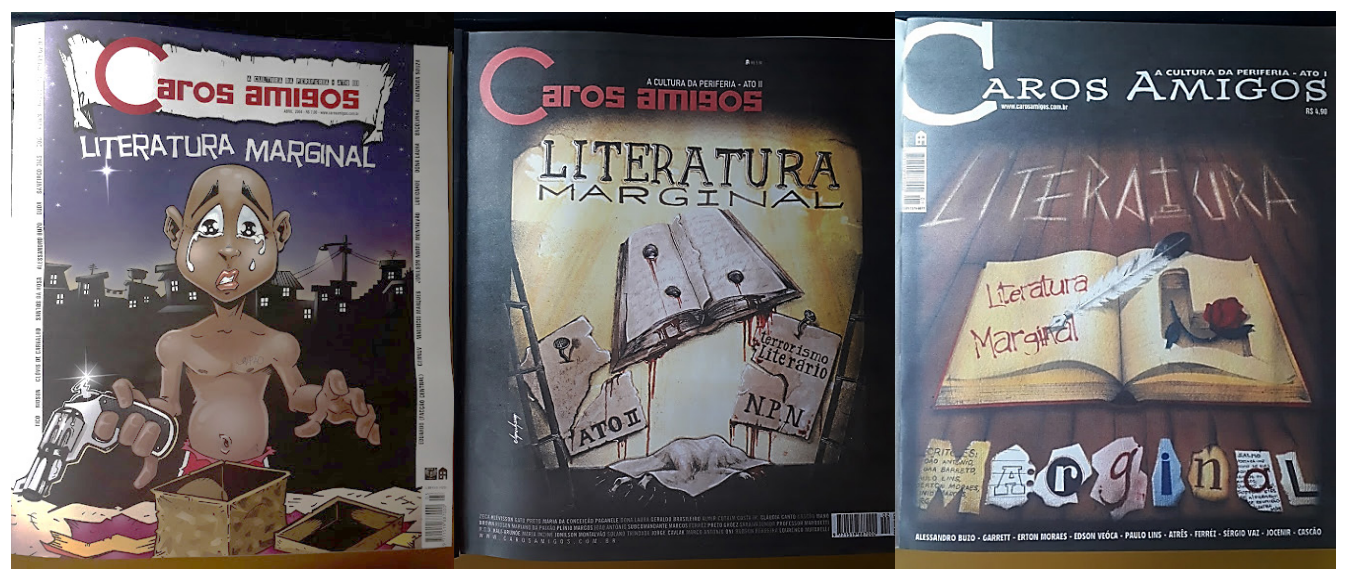

Fonte: O autor (2021).

O primeiro Ato recebeu o prêmio da Associação Paulista de Críticos de Arte (APCA), em 2002, pelo melhor projeto literário do ano (SILVA, 2011). Tal premiação pode ser considerada índice de reconhecimento de uma instituição legitimadora que percebe "qualidade" literária e artística no trabalho, além do entendimento enquanto motivação para a continuidade de uma segunda edição especial. Com isso, o prestígio acumulado do prêmio (haja vista sua posição relativa dominante dentro do campo literário) se expande 
para todos os agentes que publicaram na edição. No Ato I, dez autores foram editados: Alessandro Buzo, Erton Moraes, Paulo Lins, Ferréz, Jocenir, Garrett, Edson Véoca, Atrês, Sérgio Vaz e Cascão.

Inaugurava, assim, um universo no campo da "literatura" e da "cultura periférica", como aponta Peçanha do Nascimento (2009). A partir desses três números, Ferréz se instalou como escritor em um lugar que o situa como parte de um conjunto de escritores que, segundo ele, foram historicamente considerados incapazes de fazer literatura, já que a definição de literatura hegemônica (ligada a modos de manifestação de certo grupo e não de outros) excluía suas formas de expressão. (TENNINA, 2017, p. 229)

Como se percebe, para Lucía Tennina (2017), o ponto de mudança no campo literário voltado para um novo espaço de disputa se dá com a publicação dos três Atos da Caros Amigos. E constitui, com isso, enquanto aspiração subjetiva, uma prática objetiva de formação (ou de inauguração) de um novo espaço de produção artística no interior desse mesmo espaço simbólico.

Isso pode ser comprovado, por sua vez, no Ato $I I$, que reproduz textos não inéditos de Plínio Marcos ("Os soldados da minha rua"), de João Antônio ("Convite à vida") e de Solano Trindade ("Malungo" e "Poema para Maria Célia"), atitude que conecta a produção contemporânea a uma historicidade e, ao mesmo tempo, configura as edições dentro de uma tradição marginal para além delas mesmas, constituindo, com isso, um "cânone marginal" dentro de uma tradição em representar a periferia. Além disso, a concepção relativa ao termo "marginal" é expandida com a publicação de sete rappers, conectando, assim, a produção literária à cultura do hip hop (Gato Preto, Cascão, Mano Brown, Dugueto Shabazz, Preto Ghóez, Oni e ROD); mais dois indígenas (Káli-Arunoé e Maria Inzine); e, ainda, dois presidiários (Almir Cutrim Costa Jr. e Geraldo Brasileiro) (NASCIMENTO, 2009).

No Ato II, são 28 autores que publicam em 2002. Além de Ferréz e Cascão, que já haviam participado do primeiro Ato, agora aparecem treze novos escritores com textos inéditos: Zeca, Klévisson, Maria da Conceição Paganete, Dona Laura, Cláudia Canto, Ridson Mariano da Paixão, Subcomandante Marcos, Saraiva Júnior, Professor Marquetti, Jonilson Montalvão, Jorge Cavlak, Marco Antônio e Robson Ferreira.

Em 2004, surge o terceiro e último Ato das edições especiais. Nomes como de Alessandro Buzo, Jonilson Montalvão, Dona Laura, Ridson Mariano, Dugueto Shabazz, Atrês, Gato Preto e Preto Ghóez, que já haviam participado das outras edições, reaparecem. Contudo, outros agentes, com textos inéditos, também são incluídos, como: Revista X, v. 16, n. 6, p. 1843-1860, 2021. 
Tico, Clóvis de Carvalho, Allan Santos da Rosa, Duda, Santiago Dias, Gog, Eduardo (Facção Central), Cernov, Maurício Marques, Lutigarde, Sacolinha e Elizandra Souza.

A aproximação dos 48 autores dos 3 Atos das edições especiais se dá pelo lugar de enunciação, em uma reconfiguração própria do termo "literatura marginal", diferentemente da geração mimeógrafo ${ }^{5}$, que na contemporaneidade está vinculada ao lugar de enunciação de onde eles e elas escrevem, com isso: "A matéria-prima literária e o que uniria esses escritores, portanto, estaria dada a partir de seu lugar de enunciação, do qual ele não poderia ou não deveria abrir mão" (SILVA, 2011, p. 104). Além disso, os três Atos - e seus autores - se tornam representantes da cultura da periferia na medida em que, a partir do processo coletivo de publicação, são legitimados por Ferréz, e também no momento em que esses agentes anônimos publicam ao lado de outros escritores que possuem legitimação relativa dentro do campo literário - como Plínio Marcos e João Antônio, por exemplo.

A reunião de autores e, secundariamente, de textos que compõe uma revista literária tem como princípio verdadeiro, como se vê, estratégias sociais próximas das que presidem à constituição de um salão ou de um movimento - ainda que levem em conta, entre outros critérios, o capital propriamente literário dos escritores reunidos. E essas próprias estratégias têm como princípio unificador e gerador não alguma coisa como o cálculo cínico de um banqueiro de capital simbólico [...], mas um habitus comum ou, melhor, o ethos que é uma dimensão dele e une os membros do que se chama de "núcleo". Esse grupo ou essa rede já constituída coopta colaboradores mais ou menos regulares, determinando em particular o sumário dos primeiros números, ele próprio destinado a funcionar, pelo "que representa", isto é, certo prestígio propriamente literário, e também certa linha políticoreligiosa, como lugar de agrupamento ou contraste, ou, em todo caso, como referência nas lutas de classificação de que o campo é o lugar. (BOURDIEU, 1996, p. 307, grifos do autor)

\footnotetext{
5 "Existem, portanto, diferenças programáticas entre a década de 1970 e 1990, no que tange à ideia de Literatura Marginal. No caso dessa última, anuncia-se num certo sentido a ideia de um projeto, em que se formula a indissociabilidade entre o vivido e o narrado, cujo apego não se dá no plano passageiro. $\mathrm{O}$ fato da antologia sair por uma editora comercial de circulação nacional não invalida, para Ferréz, a proposta dos escritores marginais dos anos 90, como faria à Geração do Mimeógrafo. Ao contrário, é passo pensado e desejado, mesmo em suas produções individuais. Além disso, a antologia anuncia a fundação de uma Editora Literatura Marginal, da qual Ferréz seria o editor, organizador e criador do projeto, tendo como os primeiros a se agradecer, sendo mentores intelectuais, João Antônio, Plínio Marcos e Afonso Henriques de Lima Barreto" (SILVA, 2011, p. 105).
} 
As três edições tornam-se, com isso, marco importante quando associadas à produção marginal das periferias ${ }^{6}$, quando relacionadas às produções de outros agentes que são impulsionados a partir de sua contribuição na Revista e, dentro dessa lógica, são significativas quando os três Atos são percebidos dentro das disputas internas por reconhecimento e prestígio no interior do campo literário. Érica Peçanha do Nascimento (2009), por sua vez, destaca quatro aspectos significativos sobre a importância das três edições especiais:

O primeiro é que a reunião dos autores em edições especiais de literatura é uma ação coletiva sustentada por um projeto intelectual comum, cujo desdobramento é também estético, político e pedagógico. Em segundo lugar, porque é a partir da primeira edição da revista que se amplia o debate (e os discursos) em torno da expressão literatura marginal na produção cultural contemporânea. $O$ terceiro aspecto é que essas revistas são os veículos de entrada de boa parte dos escritores no campo literário. O quarto é que a revista Caros Amigos é uma conexão importante para fazer circular nacionalmente a produção desses escritores. E, por fim, porque o conjunto das edições especiais pode ser visto como uma das instâncias de apropriação e de legitimação dessa produção marginal. (NASCIMENTO, 2009, p. 52-53)

A Revista Caros Amigos - enquanto detentora de amplo reconhecimento e prestígio - contribui, desse modo, para que esses mesmos capitais simbólicos sejam transferidos para quem nela publica. Sem dúvidas, ela insere no campo literário diversos escritores até então desconhecidos. Com isso, as edições especiais participam na formação de um novo setor literário voltado para a publicação da literatura marginal das periferias.

\footnotetext{
${ }^{6}$ A escolha consciente de juntar os dois termos (marginal e periferia) está embasada primeiramente, na opção em manter a "marginalidade" em que os textos são construídos e dentro de uma positivação desse termo. Por outro lado, o "periferias" (ou a sua adjetivação, "periférica") se apresenta enquanto ideia geossocial em que determina tanto o espaço material de onde os escritores produzem a sua ficção, mas também aquilo que o discurso em si possui quanto ao olhar que esses autores dão para o seu texto e para as representações que apresentam. De todo modo, "literatura marginal das periferias" faz referência a escritores que são oriundos de periferias, que a partir dessa(s) mesma(s) margem(ns) constroem o seu imaginário - não falando apenas $d a$ ou sobre a periferia, mas a partir dela e, dessa maneira, produzem um modo de ser no mundo, um lugar de enunciação. Além disso, os escritores produzem movimentações identitárias para si e para suas personagens (abordando, com isso distintos imaginários possíveis para diferentes grupos sociais) e estetizam suas obras a partir de outras referências que não somente aquelas canonizadas, mas misturam, com isso, diferentes mídias, outros gêneros textuais e elementos de sua própria realidade, um deles, a oralidade.
} 


\section{TRÊS ATOS POÉTICOS}

Os poemas abaixo foram retirados de cada um dos três Atos da Revista e selecionados de modo a apresentar, de maneira ampla, novas abordagens e relações traçadas dos autores para com uma nova atitude poética contemporânea.

O primeiro texto é de autoria de Edson Veóca, morador da Cidade de Deus, periferia localizada na cidade do Rio de Janeiro. O autor já publicou outros livros, como Favos $^{7}$ e Os sentidos (2019). Além de "Pai e eu", o poeta também publica na edição de 2001 outros três poemas: "Há chacina", "No beco que a cimeira não viu" e "Descaso, o cerol do gueto". Essas informações comprovam que o escritor já vinha investindo em sua trajetória como agente literário. De todo modo, esses elementos contribuem para uma visão geral acerca do trabalho empreendido por Edson.

Pai e eu

1 Era manhã, eu era menino.

2 Meu pai caminhava

3 por dentro do sol.

4 Muitos outros pais

5 o sol atravessavam.

6 Partia meu pai

7 para o trabalho braçal e pesado

8 no norte de criar as crias

9 sem que faltassem pão e farinha.

10 Essa agonia cotidiana de anos,

11 Do rosnar incômodo do motor

12 do ônibus lotado.

13 Vezes eu via

14 o olhar fixo de meu pai.

15 E num de repente,

16 de raio rachando as nuvens,

17 de vento sudoeste apagando as velas,

18 ele sacudia o crânio

19 para afugentar os gritos deste cotidiano,

20 as sombras do desemprego,

21 as garras da ditadura.

22 Esses pregos

23 perfuravam-lhe a vida,

24 os poros, os sonhos.

25 Livre só era

26 na mínima fração

27 de chegar em casa tarde, esgotado,

\footnotetext{
${ }^{7}$ Até o momento da escrita deste artigo, não foi possível encontrar o ano de publicação do livro.
} 
28 com cinco balinhas juquinha no bolso,

Junto a "Pai e eu" há uma ilustração de um homem crucificado, em referência a Jesus Cristo. Do mesmo modo como a tradição cristã, no desenho o homem está sem camisa, contudo, possui em sua mão uma chave de fenda, na cabeça, um capacete de carpinteiro e, na cintura, um cinto de utilidades gerais comumente utilizado por trabalhadores dessa profissão. A ilustração, com isso, contribui para possíveis interpretações relacionadas ao pai no sentido do sacrifício que a figura paterna desempenha em relação à sua família, uma vez que há referência direta no poema aos "pregos" que perfuram a vida desse homem e também à restrição de sua liberdade, uma vez que o pai passa o dia no trabalho e só é livre quando chega em casa.

Por meio do verso livre, o eu-menino do poema constrói sua visão acerca do pai. O olhar com admiração da criança para o seu pai que percebe neste homem um exemplo a ser seguido, mas também vê nele as dores e os sofrimentos do cotidiano, seja no ônibus que encara todos os dias, ou na percepção do medo do desemprego, por exemplo. Essa mesma visão da criança é capaz de construir imagens muito bonitas, como a dos versos 2 e 3: "Meu pai caminhava/ por dentro do sol", em uma possível referência ao enfrentamento dos desafios do cotidiano, além da longa duração da jornada, como de ir a uma ponta a outra do sol, do nascente ao poente; ou a dos versos 4 e 5: "Muitos outros pais/ o sol atravessavam". O poeta, com isso, muda a ordem sintática direta, altera a lógica natural, em que a luz do sol atravessa os seres, para construir uma imagem na qual a grandiosidade das figuras paternas é capaz de atravessar as maiores adversidades.

O poema a seguir, "Um presente para a Elite Brasileira", faz parte do Ato II, de 2002. A autora, Cláudia Canto, mora na Cidade Tiradentes, bairro do extremo leste de São Paulo. Ainda em 2002, a partir de sua experiência como empregada doméstica na Europa, escreveu Morte às vassouras, o diário de uma jornalista que se tornou empregada doméstica em Portugal. Depois disso, publicou ainda outros 10 livros entre biografias, contos, crônicas e poemas.

Um presente para a Elite Brasileira

1 Dou de presente uma navalha na carne

2 Meu sangue de mulher, para os famintos de cultura

3 Me masturbo perto dos galãs e cuspo nos seus cérebros vazios e vis...

4 Cambaleio diante dos tribunais, maldizendo os répteis que só enxergam [bundas 
5 Dou de presente

6 Mulheres negras de atitude e enalteço seus cabelos de carapinhas

7 Dou a admiração dos covardes

8 A sintonia dos loucos

$9 \mathrm{E}$ a magnitude dos poetas

10 Grito palavras de desassossego, sãs e loucas

11 Infiltrarei um marginal em cada universidade para mostrar do que somos [capazes

12 Dou de presente

13 Uma Língua Portuguesa diferente, aprendida no gueto

14 Poesia marginal e o Chico Buarque da periferia

$15 \mathrm{E}$ haverá um dia em que chegarás perto do belo,

16 Este mesmo que as estatísticas quiseram apontar como feio

17 Aprenderás o que é anseio à flor da pele

18 Dou de presente

19 Sem teto, sem pão, sem inglês, sem francês, sem computador...

20 Com ódio, com sangue nos olhos, com armas, sede de vingança

21 Marginais permanentemente enfurecidos, dispostos a morrer para mudar

22 O rumo desta gotinha que cai da sua janela (CANTO, 2002, p. 11)

O presente ofertado pelo eu-lírico feminino do poema se constrói no tom irônico que impregna todo o texto, explicitamente através da repetição de "Dou de presente", que encabeça todas as estrofes. Além disso, evidencia-se a presença do corpo no poema, de um corpo negro feminino marginalizado pela elite brasileira. Nesse entremeio, entre a materialidade de um corpo associada à ironia do sujeito, a reflexão perpassa todo o poema e aprofunda a crítica social na comparação entre diversos outros sujeitos que aparecem no texto: poetas, marginais, loucos, mulheres negras, etc. A dicotomia - ou a comparação -, explicitamente na terceira estrofe, nos versos 15 e 16, é apresentada ao leitor: "E haverá um dia em que chegarás perto do belo, / Este mesmo que as estatísticas quiseram apontar como feio". Aquele mesmo sujeito que a elite brasileira, por meio de suas estatísticas, qualifica como feio, na voz do eu-lírico, contudo, é reconhecido como belo. No entanto, o uso do termo "estatísticas" levanta questões sobre a existência, efetivamente, de uma sondagem ou de uma coleta de dados que interrogue o que é belo ou feio. A mudança valorativa segue, com isso, na leitura do contexto social percebida na crítica que a poeta faz à sociedade brasileira.

Além disso, há reflexão sobre uma nova língua, uma língua portuguesa que não vem de regras e predicativos hegemônicos, mas que se constrói espontaneamente 
nos becos e vielas dos guetos das periferias. Uma linguagem inscrita no corpo negro e atualizada na poesia marginal do século XXI, que, no agora presentificado do tempo, poderá entregar um novo Chico Buarque ${ }^{8}$, mas oriundo das favelas brasileiras. Por meio dessa estratégia, Cláudia Canto insere e percebe a produção contemporânea dentro de uma "tradição" literária de falar sobre o contexto social, em outras palavras, o ponto de contato entre esses dois períodos estaria no conteúdo dos versos dos poemas. No entanto, a diferença entre ambos os movimentos pode ser encontrada no próprio conceito de marginalidade: enquanto os autores dos anos 1970 e 1980 se colocavam dentro desse termo, os do século XXI foram postos à margem da sociedade.

O terceiro poema aqui proposto para reflexão é "Conflito", publicado no último Ato da Revista, em 2004. Atrês, autor do texto, é MC do grupo Otraversão, do Capão Redondo, periferia da Zona Sul de São Paulo. A informação sobre o autor está disponível no pé da página, mas até o momento não foi possível encontrar outros dados sobre a trajetória do poeta. No entanto, em Capão pecado, primeiro romance de Ferréz, publicado em 2000, há um texto de abertura de uma das partes do livro de autoria de Otraversão que poderia ser atribuído ao rapper.

\section{Conflito}

1 Talvez se apenas os olhos eu fechasse

2 Não, não. Mesmo assim o mundo não desaparece.

3 A vida é uma viagem muito confusa

4 A certeza é que sempre haverá dúvida

5 Talvez se eu fosse como o Raul Seixas

6 Uma metamorfose ambulante ou um maluco beleza

7 Ou que queira sentir outras experiências

8 A realidade incomum como Carlos Castañeda

9 Talvez ainda procure vida inteligente na Terra

10 Que possivelmente somos parte de uma experiência genética

11 Que também queira conhecer plantas e estrelas

12 Só que a Nasa não vai me fazer essa gentileza

13 Talvez não acredite que já é o $2^{\circ}$ milênio

14 Se ainda tem gente de fome morrendo

15 Quero ser a visão do vendo sem rumo nem direção

16 A brisa na cara de quem trabalha lá no sertão

\footnotetext{
${ }^{8}$ A referência a Chico Buarque também se relaciona ao fato de que o autor e músico fez parte do dossiê, organizado por João Antônio, da Revista de São Paulo Extra, de março de 1977, "Malditos escritores!", remetendo, assim, à geração mimeógrafo. Por outro lado, também remete à posição de prestígio hoje ocupada pelo escritor e músico brasileiro.
} 
17 Talvez o início da vida, um risco, um aborto

18 A morte intencional por ser um desgosto

19 O sofrimento expresso no olhar da criança

20 Que largaria o trabalho para ter de volta a infância

21 Talvez o filho que recebe um tiro

$22 \mathrm{E}$ a notícia que pega o pai desprevenido

23 Desce a lágrima no rosto de quem não se contém

24 De querer esperar alguém e saber não vem

25 Talvez o destino seja uma conspiração divina

26 Por isso o ser humano se acomoda e se subestima

$27 \mathrm{E}$ tudo não passe de um conto de fadas

28 Que cheira a ilusão para encontrar a terra encantada

29 Talvez a cada minuto, momento ou instante

30 Eu sinta a paz cada vez mais distante

31 Porque é difícil reconhecer o erro e voltar atrás

32 Agora é necessária a guerra para alcançar a paz

33 Talvez seja mais um romântico idealista

34 Frio, calculista, verdadeiro e realista

35 Que, quanto mais refletia, menos compreendia

36 O que fomos, que somos ou o que seremos um dia(ATRÊS, 2004,p. 15)

Diferentemente dos outros dois poemas aqui analisados, o texto de Atrês possui certa regularidade: com estrofes de quatro versos e com alguns versos rimados na última sílaba. Como, por exemplo, nos dois primeiros versos da última estrofe: "Talvez seja mais um romântico idealista/ Frio, calculista, verdadeiro e realista" (grifos meus) - o trecho ainda possui rima interna com "calculista", que aumenta ainda mais a tensão do texto. As duas hipóteses teóricas expostas ao final de cada verso expõem o conflito do sujeito lírico sobre sua identidade. Embora opostas dentro da tradição filosófica, elas funcionam no poema como índices relativos de contradição, enquanto ambiguidade de um eu em conflito - consigo mesmo e com o mundo ao seu redor. Pode-se depreender também, a partir das rimas, a influência do rap na construção da estrutura do poema, além da denúncia de problemas sociais que é típica desse gênero musical e que se comprova na menção ao trabalho infantil, na quinta estrofe, por exemplo. "Conflito", se encarado em diálogo com o rap - Rhythm and Poetry (ritmo e poesia) -, traz para o jogo contemporâneo de escrita de poesia mais um aspecto: o de falar sobre o meio social no qual o poeta está inserido e criticá-lo contundentemente. Desse modo, associa gírias e reflexão próximas de uma realidade marginal que é exposta no texto poético. 
Cada uma das estrofes é iniciada pelo advérbio "talvez", que indica, por sua vez, possibilidade, mas não certeza. O conflito do eu lírico se mostra, com isso, nas incertezas que o cercam, na possibilidade de haver alguma mudança no seu meio social. A mudança também é evocada no poema por meio da comparação entre o eu lírico e Raul Seixas, ambos identificados enquanto metamorfoses ambulantes. Além da referência a Carlos Castañeda, considerado ícone da contracultura e do movimento hippie a partir de seus livros - especialmente, A erva do Diabo, de 1968. Desse modo, a centralidade da voz do sujeito está colocada à margem, a qual, na primeira estrofe, reflete sobre si, faz relações com outros (na segunda estrofe), que expande sua visão sobre o planeta Terra (na terceira) e na quarta estrofe foca no espaço específico do sertão. A movimentação do olhar do poeta se constrói, dessa maneira, de si para o mundo, para uma totalidade que precisa do conflito para encontrar a paz e poder compreender, em alguma medida, "O que fomos, que somos ou o que seremos um dia".

\section{ATO POLÍTICO}

Nos trabalhos críticos e teóricos de Érica Peçanha do Nascimento (2009) e no de Lucía Tennina (2017) fica evidente o impacto que as três edições especiais da Revista Caros Amigos/Literatura Marginal tiveram no campo literário, mas, sobretudo, para os agentes - e possíveis novos produtores culturais - que se identificaram com os escritores que publicaram nos três números. Em alguma medida, dentro de uma história da literatura marginal das periferias, a Caros Amigos/Literatura Marginal inaugura um novo momento dentro da literatura brasileira, que se volta para a representação de realidades de sujeitos à margem que agora são escritas por esses mesmos sujeitos oriundos das periferias brasileiras. Como exemplo, em 2005, Ferréz organiza o livro Literatura Marginal: talentos da escrita periférica, pela Editora Agir, vinculada à Casa Amarela (a mesma que publicou as edições especiais da Caros Amigos/Literatura Marginal), reunindo na obra alguns dos textos (contos, crônicas e poemas) publicados na Revista ao longo de 2001, 2002 e 2004, e outros 15 inéditos. Tal fato comprova o esforço em consolidar e apresentar distintos agentes para a cena literária nacional. Em outras palavras, o projeto especial da Revista se expande e inclui novos agentes no campo, mas, acima de tudo, mostra novas possibilidades coletivas de trazer visibilidade e legitimidade para os escritores das periferias, que nem sempre encontram espaço no mercado editorial hegemônico. No livro Literatura Marginal, contudo, Edson Veóca, Cláudia Canto e Atrês não foram incluídos.

Entre os onze escritores que publicaram no livro, apenas Luiz Alberto Mendes, com o conto "Cela forte", não participou de nenhuma das três edições da Caros Amigos/ 
Literatura Marginal. Além disso, Dona Laura (com os contos "Os olhos de Javair" e "A vingança do brechó", publicados nos Atos I e II, respectivamente) é a única mulher presente. Dos 25 textos (entre poemas e contos) publicados, 15 são inéditos (ao menos, em relação às edições especiais da revista) e os outros apareceram em algum dos três números.

A ação coletiva dos autores, ao mobilizar a publicação agora em forma de um livro, possibilita entrever que os agentes atuam diretamente no campo literário brasileiro e, ao mesmo tempo, sofrem as ações desse espaço simbólico, de maneira a disputar reconhecimento e prestígio:

É tão verdadeiro quanto falso dizer que as ações coletivas produzem $\mathrm{o}$ acontecimento ou que elas são seu produto. $\mathrm{Na}$ verdade, elas são o produto de uma conjuntura, isto é, conjunção necessária das disposições e de um acontecimento objetivo. A conjuntura política (por exemplo, revolucionária) só pode exercer sua ação de estímulo condicional atraindo ou exigindo uma resposta determinada dos que a apreendem enquanto tal, sobre aqueles que estão dispostos a constituí-la enquanto tal porque são dotados de um determinado tipo de disposições passíveis de serem redobradas e reforçadas pela "tomada de consciência" quer dizer, pela posse, direta ou mediata, de um discurso capaz de assegurar o domínio simbólico dos princípios praticamente dominados do habitus de classe. É na relação dialética entre as disposições e o acontecimento que se constitui a conjuntura capaz de transformar em ação coletiva as práticas objetivamente coordenadas, porque ordenadas a necessidades objetivas parcial ou totalmente idênticas. (BOURDIEU, 1983, p. 76, grifos do autor)

A ação coletiva, desse modo, se concretiza na medida em que Ferréz ocupa um espaço enquanto escritor fixo da Caros Amigos e em outros veículos de comunicação. Em outras palavras, ele traz consigo para o espaço possível da produção das edições especiais o seu capital de prestígio acumulado até o momento. Nesse meio, a partir da tomada de consciência de outros agentes com habitus e disposições necessárias semelhantes, é possível pensar na agregação de uma coletividade em torno de uma produção/ação comum. Na virada do século XX para o XXI, desse modo, acrescentadas nessa conjuntura todas as mudanças históricas desse período no Brasil (especificamente a mudança do espectro político no Executivo, com as políticas públicas para educação e cultura, por exemplo), mais a percepção dos sujeitos sobre o espaço que ocupam na sociedade, tornase possível efetivar o projeto da literatura marginal.

A produção de um livro confirma certo sucesso relativo do projeto da Caros Amigos/ Literatura Marginal. Explicitamente no texto de abertura do livro, Ferréz acrescenta a noção que compreende a palavra entendida para além do discurso, vista, então, enquanto, 
ação. Ação coletiva da escrita que se insere ativamente no jogo por espaços dentro do campo literário - jogo de poder que constitui o discurso. É importante destacar, nesse contexto, a transposição dos textos da Revista para a forma (compreendida dentro da sua apreciação comumente tida, por excelência, como hegemônica) de livro. Por si só, esse formato editorial pode ser entendido como objeto estético e cultural que poucos teriam acesso de produção. Relegado, nesse sentido, a uma parcela dominante dentro dos meios de produção artísticos. Quando um autor em início de sua trajetória ${ }^{9}$, como é o caso de Ferréz, reúne outros escritores (em sua grande maioria que estão ingressando no campo literário) para publicar um livro, é impossível pensar que o campo literário tenha ficado imune a esse tipo de publicação. No entanto, através de uma ação coletiva, começa-se a delinear uma nova estrutura (em alguma medida independente ou criando instâncias independentes) do campo literário hegemônico. O texto de abertura do livro, "Terrorismo literário", por sua vez, comprova certa independência da nova produção literária ao afirmar que não precisa da legitimação de alguém de fora desse contexto:

Somos mais, somos aquele que faz a cultura, falem que não somos
marginais, nos tirem o pouco que sobrou, até o nome, já não escolhemos
o sobrenome, deixamos para os donos da casa-grande escolher por nós,
deixamos eles marcarem nossas peles, por que teríamos espaço para
um movimento literário? Sabe duma coisa, o mais louco é que não
precisamos de sua legitimação, porque não batemos na porta para alguém
abrir, nós arrombamos a porta e entramos. (FERRÉZ, 2005, p. 10)

O projeto das três edições especiais associado à sua publicação em forma de livro são dois pontos importantes na história da literatura marginal das periferias, pois concretizam e evidenciam a mudança do horizonte de possibilidades que se abre a cada agente cultural em devir. O campo literário, contudo, continua com suas regras específicas e sua estrutura impositiva de colocação dos agentes em um lugar determinado (para o caso dos produtores periféricos, uma posição dominada e dependente de instâncias dominantes com poucas possibilidades de ascensão na estrutura do campo). Em vista disso, os mesmos agentes não se conformam com essa delimitação, atuam de modo

9 “É preciso resignar-se a admitir que há uma história da razão que não tem a razão como (único) princípio. Para explicar o fato de que a arte - ou ciência - parece encontrar em si mesma o princípio e a norma de sua mudança, e de que tudo se passa como se a história fosse interior ao sistema e o devir das formas de representação ou de expressão não fizesse mais que exprimir a lógica interna do sistema, não há necessidade de hipostasiar, como se fez muitas vezes, as leis dessa evolução. 'A ação das obras sobre as obras', de que fala Brunetière, sempre se exerce tãosomente por intermédio dos autores cujas estratégias devem também sua orientação aos interesses associados à sua posição na estrutura do campo" (BOURDIEU, 1996, p. 226). 
contundente, demonstram a força da cultura periférica e criam os seus meios de produção e de reconhecimento de suas obras - como selos e editoras, prêmios, organizações e outras ações coletivas.

Desse modo, retornando aos poemas aqui destacados, quando analisados em conjunto, possibilitam questionamentos mais gerais relativos ao projeto como um todo da Revista (dentro de uma coletividade, a partir das produções literárias, forma-se um conceito próprio para a "literatura marginal") e sobre a ideia/conceito de fazer poesia na emergência do século XXI. A respeito deste último, prefiro me deter e refletir sobre tais manifestações artísticas e acerca da escolha consciente de atingir conceitos diretamente por meio das expressões poéticas.

É evidente o tom político de denúncia que cada um dos poemas acima apresentados possui. No entanto, não é um simples "caráter denunciatório", mas há reflexão profunda sobre o uso da palavra no lugar mais adequado, o que possibilita ao signo ultrapassar o limiar simples e unívoco de seu significante. Desse modo, o próprio significado ganha, no interior dos poemas, novos contornos, realizados no ato poético, mas relacionados com um contexto material-social. Assim, vida e poesia se coadunam de modo a evidenciar que mesmo no caráter mais dramático da existência do eu, existe possibilidade do fazer poético - como fica evidente, por exemplo, no poema "Pai e eu".

Os poemas verticalizam e focalizam espaços e realidades. A poesia, nesse contexto contemporâneo dos escritores marginais das periferias, se configura como um meio possível de reflexão sobre a sociedade (ou de denúncia) e como estímulo de transformação. Nesse sentido, quase sempre há um aspecto nos textos literários voltado para a ação de quem os lê, salientando, assim, a importância que o fazer poético deve possuir, de modo que parta de uma ação, reflita sobre ela e retorne para uma nova ação direta na realidade.

A sensorialidade externa do mundo (CANDIDO, 1996) fica explícita na interioridade criada pelos poetas e expressada nos textos. Há criação de imagens, impressões visuais, táteis e ideias que revelam intensidade sensorial e intelectual. $\mathrm{O}$ mundo criado pelos escritores está diretamente relacionado com o mundo "real", é deste que surge o incômodo (ou a inspiração) para escrever. É para esse mesmo mundo real que os poetas focam o seu esforço em fazer poesia e refletir sobre os aspectos sociais que os cercam - em sua maioria, excludentes.

Ética e estética, desse modo, estão ligadas pela ação dos sujeitos escritores. De uma preocupação ética surge uma possível estética próxima do rap - como mencionado anteriormente - e que aos poucos também se distancia desse gênero para criar formas 
poéticas mais livres, sem uma forma estanque, conforme cada autor. Nesse sentido, seria quase impossível falar em características unívocas a respeito da poesia marginal das periferias. Cada poeta atribui para si, com isso, uma forma própria de construção de seus poemas, além de dialogar com uma tradição acumulada de poesia "não-marginal" ao utilizar, por exemplo, quartetos e rimas, etc.. Por outro lado, em sua grande maioria, os escritores, quase sempre, partem de uma preocupação ética para escrever.

A exterioridade tem papel central na reflexão individual do sujeito poético. Explicitamente no caso dos poemas na Revista Caros Amigos/Literatura Marginal, a movimentação circular poética manifesta-se, dessa forma, por meio da percepção externa da realidade refletida na produção dos textos: de um coletivo, o sujeito lírico produz e volta-se para o mesmo coletivo. Em outras palavras, em um outro extremo, dentro do conjunto coletivo em que os poemas aqui trabalhados foram publicados, o(s) outro(s) se encontra(m) no "eu" em si abordado na poesia. A realidade, com isso, não é apenas um mote ou um assunto, mas torna-se também o ponto para onde retornam os poemas.

Conforme a citação de Charles Batteux apresentada no início deste texto, a finalidade da poesia seria a de agradar agitando as paixões. Nos poemas aqui trabalhados, pode-se ver uma outra face da poesia que surge do descontentamento. Em sua maioria, os textos poéticos - assim como as edições especiais da Caros Amigos/Literatura Marginal - querem atingir justamente aqueles que estão em posição semelhante aos escritores da Revista: nas periferias dos centros urbanos brasileiros, ou seja, querem agradar. Com isso, a proposta do coletivo, pegando de empréstimo as palavras de Sophia de Mello, se torna a desalienação em busca de uma revolução: "É a poesia que desaliena, que funda a desalienação, que estabelece a relação inteira do homem consigo próprio, com os outros, e com a vida, com o mundo e com as coisas" (ANDRESEN, 1977, p. 76). Conforme já mencionado, a movimentação do sujeito lírico expressada em seus poemas não está isolada, mas em profunda relação com outros sujeitos que partilham de experiências sociais semelhantes. A dicção dos poetas, por fim, se faz nessa articulação em trazer para sua arte poética experiências e linguagens oriundas das periferias, como um ato político refletido profundamente em cada poema.

\section{REFERÊNCIAS}

ANDRESEN, S. M. B. Poesia e Revolução. In: ANDRESEN, S. M. B. O nome das coisas. 3. ed. Lisboa: Edições Salamandra, 1977. p. 73-78. 
ATRÊS. Conflito. Revista Caros Amigos/Literatura Marginal: a cultura da periferia Ato III, São Paulo, n. 3, abr. 2004, p. 15.

BATTEUX, C. As belas artes reduzidas a um mesmo princípio. Tradução de: MARUYAMA, N.; RIBEIRO, A. São Paulo: Humanitas/Imprensa Oficial, 2009.

BOURDIEU, P. As regras da arte. Génese e estrutura do campo literário. Tradução de: MACHADO, M. L. São Paulo: Companhia das Letras, 1996.

BOURDIEU, P. Esboço de uma teoria da prática. In: ORTIZ, R. (org.). Pierre Bourdieu: sociologia. São Paulo: Ática, 1983. p. 46-81.

CANDIDO, A. O estudo analítico do poema. São Paulo: Humanitas Publicações/ FFLCH/USP, 1996.

CANTO, C. Um presente para a Elite Brasileira. Revista Caros Amigos/Literatura Marginal: a cultura da periferia - Ato II, São Paulo, n. 2, jun. 2002, p. 11.

FERRÉZ (org.). Literatura marginal: talentos da escrita periférica. Rio de Janeiro: Agir, 2005.

NASCIMENTO, É. P. Vozes marginais na literatura. Rio de Janeiro: Aeroplano, 2009.

SILVA, M. A. M. A descoberta do insólito: Literatura Negra e Literatura Periférica no Brasil (1960-2000). 2011. 448 f. Tese (Doutorado em Sociologia) - Instituto de Filosofia e Ciências Humanas, Universidade Estadual de Campinas, Campinas/SP, 2011.

TENNINA, L. Cuidado com os poetas! Literatura e periferia na cidade de São Paulo. Trad. Ary Pimentel. Porto Alegre, RS: Zouk, 2017.

VEÓCA, E. Pai e eu. Revista Caros Amigos/Literatura Marginal: a cultura da periferia - Ato I, São Paulo, n. 1, 2001, p. 15.

Recebido em: 30 jul. 2021. Aceito em: 23 ago. 2021. 